\title{
Adaptation of MacNew Heart Disease Health-Related Quality of Life Instrument in Indonesian Myocardial Infarction Patients
}

\author{
Devi Wulandari \\ Faculty of Psychology, Universitas Indonesia \\ Department of Psychology, Paramadina University \\ devi.wulandari@hotmail.com \\ Adriana Soekandar Ginanjar \\ Faculty of Psychology, Universitas Indonesia \\ adriana.ginanjar@yahoo.com \\ Urip Purwono \\ Faculty of Psychology, Padjadjaran University \\ urip.purwono@gmail.com
}

\begin{abstract}
Lack of adapted health-related quality of life measurement in Bahasa Indonesia may create difficulties in concluding the effects of heart disease and its treatment on a patient's health-related quality of life in Indonesia. MacNew heart disease health-related quality of life questionnaire (MacNew) has been proven a valid and reliable health-related quality of life measurement. It also has been adapted in several languages. This study aimed at translating and assessing the Indonesian version of MacNew questionnaire validity evidence based on the relation with other variables on and internal consistency. Validity evidence based on the relation with other variables was assessed by correlating the Indonesian version of the MacNew questionnaire score with cardiac anxiety, gender, age, education level, left ventricular ejection fraction score, and comorbidity. Two hundred thirty-six patients diagnosed with myocardial infarction (MI) filled out the questionnaire at a one-time intake. Results from confirmatory factor analysis revealed three domains of health-related quality of life, namely emotional, physical, and social. The three-domain explained $42.31 \%$ of the health-related quality of life total variance. The internal consistency of the questionnaire was good (0.816-0.900). Health-related quality of life was negatively correlated with cardiac anxiety. Male patients had a higher health-related quality of life compare to female patients. However, there was no significant correlation between health-related quality of life and left ventricular ejection fraction and comorbidity. The Indonesian version of MacNew questionnaire demonstrated satisfactory psychometric properties and can be recommended to measure HRQOL in heart patients in Indonesia.
\end{abstract}

Keywords: Health-related quality of life, MacNew Heart Disease HRQOL instrument, instrument adaptation

Received 2 October 2019/Accepted 30 November 2019 CJEHCP All rights reserved 


\section{Introduction}

In the past decades, health-related quality of life (HRQOL) has been examined extensively. Keywords health-related quality of experience in the Google Scholar engine revealed I,470,000 results. Although HRQOL has received much attention, the consensus regarding the definition of HRQOL remains afar. There are several definitions of HRQOL. HRQOL can be defined as the effects of health, illness, and its treatment on quality of life (Ferrans, Zerwic, Wilbur, \& Larson, 2005). Guyatt, Feeny, \& Patrick (1993) distinguish between the quality of life and HRQOL. Quality of life, health status, and functional status can be used interchangeably and infer wide aspects of life. However, HRQOL assumes more limited aspects in one's life that are affected by health. Income, the lack of freedom, and other aspects that are far from medical relations are not included in HRQOL. Cella \& Stone (20I5) define HRQOL as a general perception of the quality of life affected by the disease, its treatment, and functional limitations. Bowling (2005) stated that as one domain of broader quality of life, HRQOL could be defined as perceptions of goodness in life affected by health.

HRQOL is an important index not only for clinicians but also for patients to measure the impacts of disease and medical interventions (Guyatt et al., 1993). There are two types of HRQOL measurements, namely disease-specific measurement and generic measurement. $A$ generic measurement is not specified for a certain disease; thus, it can be used for patients with any type of disease and healthy people. Disease-specific measurement contains items that are meaningful for a disease. It is concluded that disease-specific measurement is more relevant to the patients and also more responsive to changes caused by the treatment or disease progression. Generic measurement also has its advantages that enable comparison of results across different types of disease, with a healthy population to have a better understanding regarding HRQOL (Cella \& Stone, 2015). It is also advisable to use both disease-specific and generic measurements to gather more comprehensive data (Sneed, Paul, Michel, Vanbakel, \& Hendrix, 200I).

Mortality and morbidity in Indonesia caused by cardiovascular disease are concerning. It is reported that cardiovascular disease caused more than $30 \%$ of death in Indonesia (World 
Health Organization, 2014). The increasing number of patients with hypertension and diabetes, cigarette smoking, high level of cholesterol and body weight are considered to be risk factors contributing to premature death caused by cardiovascular disease (Hussain, Peters, Woodward, Huxley\& Al Mamun, 2016; Kementrian Kesehatan Republik Indonesia, 2013). Not only death, DALY (disability-adjusted life years) caused by cardiovascular disease ranged from 10-19 years (World Health Organization, 2004). Patients with MI experienced many challenges in their life; hence, MI affected a patient's health-related quality of life. However, to the best of our knowledge, there is none health-related quality of life instruments available to assess the impact of myocardial infarction on Indonesian patients. Therefore, a validated HRQOL instrument will be beneficial to measure the effects of myocardial infarction and its treatments on a patient's HRQL.

MacNewHeart Disease HRQOL instrument (MacNew) is a self-administered disease-specific measurement that consists of 27 items. The MacNewHeart questionnaire was a modification from the Quality of Life after Myocardial Infarction questionnaire (QLMI). There are three domains in the MacNew questionnaire, namely physical limitation, emotional function, and psychological function. The MacNew questionnaire has have been adapted into 28 languages and more appropriate measures for intervention trials and routine clinical care (Höfer et al., 20I2). It is also proven to be a valid, reliable and responsive instrument to assess HRQOL in patients with myocardial infarction, heart failure, angina and ischaemic heart disease(Dixon, Lim, \& Oldridge, 2002; Höfer et al., 20I2). The MacNew questionnairewas correlated with adverse events in patients (Höfer, Lim, Guyatt, \& Oldridge, 2004). Currently, no study adapted the MacNew Heart questionnaire in Indonesia. Therefore it needs to examine whether the MacNew Heart questionnaire appropriate for Ml patients in Indonesia. This study aimed to adapt MacNew Heart Disease HRQOL into Bahasa Indonesia and examine the factor structure of it in Indonesian MI patients. 


\section{Method}

\section{Respondents}

Respondents were recruited from a national hospital in Jakarta. Before the study was conducted, ethical approval was given from the hospital and university ethical committee. Purposive sampling was employed in the study. The inclusion criteria for the study are patients diagnosed with $\mathrm{MI}$ and not diagnosed with mental illness, according to DSM IV. The questionnaire was distributed to the patients after their regular monthly visit, in a closed room to ensure confidentiality. More than $90 \%$ of the respondent prefers to do interview administered questionnaire. Two hundred fifty patients filled out the questionnaire. However, 14 patients were not included in the analysis because of the incomplete data. The response rate for the study is $94.4 \%$.

The study sample consisted of 236 respondents with a range of age 4 I-7I. There were 34 female and 197 male respondents in the study. Inclusion criteria for the study were: diagnosed with $\mathrm{MI}$ and not suffered from any mental disorder, as mentioned in DSM V. Table I showed respondents characteristic in the study. More than $50 \%$ of the respondents were above 56 years of age. There were $14.7 \%$ female and $85.3 \%$ male respondents of the study. More than $70 \%$ of the total respondents had high and higher education. As can be seen in Table I, the two most prevalent secondary diagnoses of the patients were diabetes and hypertension.

Tabel I.

Respondent's Demographic and Medical Characteristics

\begin{tabular}{lcc}
\hline Variable & $n$ & $\%$ \\
\hline Age (years) & 19 & 8.3 \\
$4 I-45$ & 26 & 11.4 \\
$46-50$ & 62 & 27.2 \\
$5 I-55$ & 50 & 21.9 \\
$56-60$ & 56 & 24.6 \\
$61-65$ & 11 & 4.8 \\
$66-70$ & 4 & 1.8 \\
$>70$ & & \\
Sex & 197 & 85.3 \\
Male & 34 & 14.7 \\
Female & &
\end{tabular}




\begin{tabular}{lll}
\hline Marital Status & 229 & 99.1 \\
$\quad$ Married & 2 & 0.9 \\
$\quad$ Single & & \\
Educational Level & 50 & 21.7 \\
$\quad$ Primary & 81 & 35.1 \\
$\quad$ High School & 98 & 43.2 \\
$\quad$ College & & \\
Comorbidity & 89 & 41.4 \\
Diabetes Mellitus & 34 & 15.8 \\
$\quad$ Congestive Heart Failure & 91 & 42.3 \\
$\quad$ Hypertension & & 66.7 \\
Treatment & 154 & \\
$\quad$ Percutaneous Coronary & & 1.7 \\
$\quad$ Intervention & & \\
$\quad$ Coronary Artery Bypass & 4 & \\
Grafting & & \\
\hline
\end{tabular}

Tabel 2 showed mean and SD for each of the MacNew questionnaire domains. The emotional domain has the highest mean, followed by a physical and social domain. Thus, it can be concluded that $\mathrm{MI}$ patients experienced better emotional responses compare to physical and social responses affected by $\mathrm{MI}$ and its treatment.

Table 2.

Descriptive Statistics of MacNew HRQOL Domains of MI Patients

\begin{tabular}{lllll}
\hline Domain & Mean & SD & Min & Max \\
\hline Emotional & 5.125 & 0.871 & 3.09 & 6.91 \\
Physical & 4.881 & 1.089 & 2.00 & 7.00 \\
Social & 4.778 & 1.055 & 1.60 & 6.90 \\
\hline
\end{tabular}

\section{Translation process}

The forward translation of the MacNew questionnaire was delivered by two independent bilingual health professionals. Differences between the two translations were resolved to achieve one appropriate MacNew questionnaire translation by the author and also from the MacNew Organization. This MacNew translation was translated again in English by two translators who have not seen the parent language version of the test. The author and MacNew questionnaire developer worked together to select the best translation. This back- 
translation was conducted several times until a satisfactory result achieved. The Indonesian MacNew questionnaire consisted of 27 items. Before distributed to the respondent, ten heart patients were given the questionnaire and interviewed to explore any language difficulties.

\section{Measurements}

The MacNew questionnaire is an HRQOL instrument that can either be self- administered and interviewer-administered. It has been tested on more than 5,200 heart patients. The instrument consists of 27 items with a seven-point Likert scale. There are three domains in MacNew questionnaire namely physical (e.g., How much shortness of breath have you experienced during the last 2 weeks while doing your day-to-day physical activities?) psychological (e.g. how often in the last two weeks have you felt worthless and inadequate?) and social wellbeing (e.g. how often during the last two weeks have you felt you were unable to do your usual social activities, or social activities with your family?) (Dixon et al., 2002). The score of each item ranges from I (all of the time) to 7 (none of the time) with a higher score means higher HRQOL. For each of the three-domain, averaged response of each domain. The global score derived from the averaging response from all 27 items. (Dixon et al., 2002). If 50\% of the response for each domain is missing, the score for that domain is considered missing. Studies show that the MacNew questionnaire has good reliability. It is also predicted adverse cardiac events, responsive and sensitive to changes in HRQOL due to interventions (Höfer et al., 2004). The scoring system of the adapted questionnaire follows the instruction for the originally developed MacNew questionnaire. The maximum score for the questionnaire is 7 (high HRQOL), and the minimum is I (low HRQOL). A higher score indicating higher HRQOL. In order to evaluate the three domains, each score from each domain was derived from averaging items that contribute. Average of scores from 13 items will constitute a score for physical limitation. Average of 14 items will make up the score for the emotional function domain, and the mean of 13 items will result in a score for the social function domain. The score for global HRQOL will be derived from averaging scores from 27 items.

Cardiac anxiety was measured by the Cardiac Anxiety Questionnaire (CAQ). CAQ is a Likert type scale consisted of 18 items with five answering options, form 0 (never) to 4 
(always). The score for total and subscale obtained from the mean score. A higher score of CAQ indicated higher cardiac anxiety. Factor analytic study revealed three subscales, namely fear regarding heart disease (e.g., I worry that I may have a heart attack), escaping behavior (e.g., I avoid physical exertion), and attention focused (e.g., I pay attention to my heartbeat). CAQ is a valid and reliable instrument and proven to be different from general cardiac anxiety measurement (Van Beek et al., 2012). In this study, the Cronbach $\alpha=0.808$ for the overall measure, indicating good internal consistency.

Left ventricular ejection fraction (LVEF) is a measurement for the cardiac function to pump blood (DeSilva, 2013). The score for LVEF was gathered from the patient's medical report. The higher percentage of LVEF indicated better cardiac function. For the study, the score of LVEF will be categorized into moderate to severe $(\leq 40 \%)$ and normal to mild $(>40 \%)$. Comorbidity was indicated by the Charlson Comorbidity Index $(\mathrm{CCl})$ score, which summed up the number of comorbidities reported by patients. The $\mathrm{CCl}$ obtained by using weighted factors based on disease severity. The $\mathrm{CCl}$ is known to measure patients' comorbidity (Charlson, Pompei, Ales, \& MacKenzie, 1987; H.-Y. Wang, Chew, Kung, Chung, \& Lee, 2007). The higher the $\mathrm{CCl}$ score, the more patients have a comorbid condition.

\section{Statistical analysis}

The patient's demographic data, internal consistency, and validity evidence based on relations with other variables were calculated using IBM SPSS Statistics 20. For demographic data, mean and SD were used to describe descriptive statistics of the data. To tested the measurement model of the MacNew questionnaire, confirmatory factor analysis with three domains, namely physical limitations, social function, and psychological function, was conducted by using MPlus 7. Internal consistency was examined with Cronbach Alpha. Evidence-based on relations with other variables validity was examined by association between HRQOL and variables that proved to be correlated with HRQOL namely cardiac anxiety(Van Beek et al., 20I2), age(Longmore et al., 20II; Muhammad et al., 20l4), gender(Ahmad, Muhammad, \& Abdullah, 20II; Bergman, Malm, Karlsson, \& Berterö, 2009; Hosseini, Ghaemian, Mehdizadeh, \& Ashraf, 20I4; Norris et al., 2008), left ventricular ejection fraction (LVEF)(Pettersen, Kvan, Rollag, Stavem, \& Reikvam, 2008), educational 
level(Choo, Burke, \& Pyo Hong, 2007; Norekvål et al., 2010) and comorbidity (W. Wang et al., 20I4). Mann-Whitney was used to explore the association between HRQOL, gender, age, and educational level. Pearson product-moment analyzed the association between LVEF, $\mathrm{CCl}$, cardiac anxiety, and HRQOL.

\section{Results}

Factor analysis

Results from confirmatory factor analysis revealed that the three factors explained $42.31 \%$ of HRQOL variance. As can be seen in Table 3, the first factor that consists of the item that describes social issues in heart patients. Explained about 28.85\%. The first factor included Item 8, II, I2, I3, I7, 20, 2I, 22, 23, 24, 25, 26, 27 were loaded $\geq 0.40$. The second factor, which describes emotional issues, explained $7.41 \%$ and consisted of the item that was loaded $\geq 0.40$ were item I, $2,4,5,7,8,10$, and I8. The last factor explained physical issues in $\mathrm{MI}$ patient's life, explained $6.05 \%$ of the total variance. The physical factor comprises item 3, 6, 9 , 14, 16, 17, and 19 has factor loading $\geq 0.40$ in the physical domain. Item 8,17 were loaded in more than one factor with factor loading $\geq 0.40$.

Table 3.

Results of Confirmatory Factor Analysis of the Indonesian version of MacNew Questionnaire

\begin{tabular}{|c|c|c|c|c|}
\hline Item & & Social & Emotional & Physical \\
\hline I. & Frustrated & & $\underline{0.583}$ & \\
\hline 2. & Worthless & 0.339 & 0.439 & \\
\hline 3. & Confident & & & $\underline{0.432}$ \\
\hline 4. & Down in the dumps & & $\underline{0.788}$ & \\
\hline 5. & Relaxed & & $\overline{0.482}$ & 0.343 \\
\hline 6. & Worn Out & & & 0.524 \\
\hline 7. & Happy with Personal Life & 0.344 & $\underline{0.443}$ & \\
\hline 8. & Restless & $\underline{0.405}$ & $\overline{0.405}$ & \\
\hline 9. & Short of Breath & & & $\underline{0.728}$ \\
\hline 10. & Tearful & & $\underline{0.762}$ & \\
\hline II. & More Dependent & $\underline{0.577}$ & & \\
\hline 12. & Social Activities & 0.587 & 0.255 & \\
\hline 13. & Other/less Confidence in you & $\overline{0.472}$ & 0.371 & \\
\hline 14. & Chest Pain & & & $\underline{0.668}$ \\
\hline 15. & Lack Self-Confidence & 0.390 & 0.360 & 0.349 \\
\hline 16. & Aching Legs & & & $\underline{0.501}$ \\
\hline
\end{tabular}




\begin{tabular}{|c|c|c|c|c|}
\hline 17 & Sports/Exercise Limited & $\underline{0.601}$ & & 0.429 \\
\hline 18 & Frightened & & 0.612 & $\overline{0.314}$ \\
\hline 19 & Dizzy/Lightheaded & & & $\underline{0.509}$ \\
\hline 20 & Restricted or Limited & $\underline{0.742}$ & & \\
\hline 21 & Unsure about Exercise & $\underline{0.57 I}$ & & \\
\hline 22 & Overprotective Family & $\underline{0.485}$ & & \\
\hline 23 & Burden on Others & $\overline{0.492}$ & 0.340 & \\
\hline 24 & Excluded & $\underline{0.572}$ & & \\
\hline 25 & Unable to Socialize & 0.612 & & \\
\hline 26 & Physically Restricted & $\underline{0.733}$ & & \\
\hline 27 & Sexual Activities & $\underline{0.543}$ & & \\
\hline & riance explained & $28.85 \%$ & $7.41 \%$ & $6.05 \%$ \\
\hline
\end{tabular}

Internal Consistency

Cronbach $\alpha$ coefficients for the global scale were 0.900 for the physical limitation domain was $0.85 \mathrm{I}$ for the social function domain was 0.869 and for the psychological function was $0,8 \mathrm{II}$. Thus, it can be concluded that Indonesia version of $\mathrm{MacNew}$ questionnaire showed acceptable internal consistency (Field, 2009).

Tabel 2.

Cronbach's Alpha Coefficient of Adapted MacNew

\begin{tabular}{|c|c|c|c|}
\hline Scale & $\begin{array}{l}\text { Number of } \\
\text { items }\end{array}$ & Cronbach's $\alpha$ & $\begin{array}{l}\text { Item-Total } \\
\text { Correlation }\end{array}$ \\
\hline Emotional & 14 & 0.816 & $0.237-0.607$ \\
\hline Physical & 13 & 0.851 & $0.348-0.68 I$ \\
\hline Social & 13 & 0.869 & $0.324-0.697$ \\
\hline Total & 27 & 0.900 & $0.250-0.643$ \\
\hline
\end{tabular}

Evidence-based on relations with other variables validity

Evidence-based on relations with other variables validity will be explored by correlating HRQOL score with cardiac anxiety, age, gender, LVEF, educational level, and score of Charlson comorbidity index. The total score of HRQOL was negatively correlated with cardiac anxiety $r=-0.552, P<0.000$. The higher the cardiac anxiety, the lower the patient's HRQOL. HRQOL in male respondent were significantly higher compare to female 
respondent $U=239.5, z=-2.238, P<0.05$. There were no significant differences in HRQOL between respondent age group and educational group. Pearson correlation revealed that there is no significant association between LVEF and CCI and HRQOL score.

\section{Discussion}

$\mathrm{Ml}$ prevalence in Indonesia has increased exponentially. More information regarding $\mathrm{MI}$ patient's HRQOL is needed not only to gain insight into the challenges faced by the patients but also to create a suitable intervention to improve HRQOL. Therefore, it is necessary to provide a valid and reliable HRQOL instrument in Bahasa, Indonesia. Statistical analysis conducted in the study revealed that the Indonesian version of the MacNew questionnaire is a valid and reliable instrument. The instrument showed an acceptable internal consistency, for global and also domain score. Several MacNew adaptations such as in Brazilian, Dutch and Norwegian also showed acceptable internal consistency (De Gucht, Van Elderen, Van Der Kamp, \& Oldridge, 2004; Hiller, Helvik, Kaasa, \& Slørdahl, 2010; Nakajima, Rodrigues, Gallani, Alexandre, \& Oldridge, 2009). For evidence-based correlation with other variables' validity, the Indonesian version of the MacNew questionnaire score has a negative correlation with cardiac anxiety. The result of the study was also supported by several studies (Blakemore et al., 20I4; Hosseini et al., 20I4; Kepka et al., 20I3; Van Beek et al., 2012). The study also found that female patients' HRQOL was lower compared to male patients. This result was in line with the results from several studies. Less social support, higher depressive symptom, and delayed referral were considered as contributing factors in gender differences (Martin et al., 2012; Norris et al., 2008).

The result of the study showed a three-domain of the Indonesian version of the MacNew questionnaire, namely emotional, physical, and social domains. Thus, the structure of the Indonesian MacNew questionnaire is equivalent to the parent language version. Similar results also found in several studies (De Gucht et al., 2004; Hiller et al., 2010). The most significant factor loading in the emotional domain was item 4 (down in the dumps) and 10 (tearful). The result of the study was supported by psychometric research conducted in Norwegian (Hiller et al., 2010). As concluded by several studies, feeling depressed and sad are the most common emotions experienced by myocardial infarction patients that 
correlated with HRQOL (Foxwell, Morley, \& Frizelle, 20I3; Hosseini et al., 20I4). Item 20 (restricted and limited) and 26 (physically restricted) were items that have the most significant factor loading in the social domain. Patients with myocardial infarction tend to feel fatigued and have a physical limitation and may result in social isolation (FredrikssonLarsson, Alsen, \& Brink, 2013). Items that have the most significant loading factor in the physical domain were item 9 (short of breath) and 14 (chest pain). Dyspnea and chest pain are the most common physical symptoms in Type I and Type 2 myocardial infarction. Thus, the result of the present study confirms the physical challenges experienced by patients with MI.

Results for factor analysis showed two common problems faced with instrument adaptation. First, several items were loaded in more than one domain. Second, different items were clustered in different domains compared to the original scoring system. These results correspond with the result from several original studies (Asadi-lari, Javadi, Melville, Oldridge, \& Gray, 2003; De Gucht et al., 2004; Hiller et al., 20I0).

HRQOL was not correlated with LVEF and $\mathrm{CCl}$. The result of the study proved that HRQOL is a subjective assessment regarding one's health. Guyatt et al. highlighted the low correlation between HRQOL and physiologic measures(1993). A meta-analytic study in 12 chronic studies concluded that patients gave more emphasis on mental health than physical functioning. Thus HRQOL is primarily based on psychological functioning and less on physical functioning (Smith et al., 1999).

Although the study has revealed good psychometric properties of the Indonesian version of the MacNew questionnaire, further study is needed to examine the questionnaire reproducibility and its sensitivity to detect clinical improvement. The Indonesian version of the MacNew questionnaire. Should also be explored its divergent and convergent validity.

Even though more than $70 \%$ of the respondents have high education, however, they preferred an interview administered questionnaire compare to a self-administered questionnaire. Lacked visual aid for reading and unfamiliarity with research instruments were several reasons behind this behavior. 


\section{Conclusion}

The Indonesian version of MacNew questionnaire showed satisfactory psychometric properties in the sample of Indonesian MI patients. It also confirmed good internal consistency and evidence-based on correlation with other variables' validity. The study had succeeded in exposing the psychometric properties of the Indonesian version of the MacNew questionnaire, and further exploration is still needed, especially for clinical studies in myocardial infarction patients. To ensure the sensitivity of the questionnaire, the questionnaire should be tested its reproducibility. Varied samples of heart disease patients are also needed to discover more benefits of the Indonesian version of the MacNew questionnaire in assessing heart patient's HRQOL.

\section{Acknowledgment}

Authors would like to thank the Ministry of Research, Technology and Higher Education, the Republic of Indonesia for supporting the study by grant $0424 / K 3 / K M / 2017$ and the University of Indonesia for PITMA A grant .

\section{References}

Ahmad, F., Muhammad, M., \& Abdullah, A. A. (20I I). Religion and Spirituality in Coping with Advanced Breast Cancer: Perspectives from Malaysian Muslim Women. Journal of Religion and Health, 50(I), 36-45. https://doi.org/I0.1007/s I 0943-0 I0-940 I-4

Asadi-lari, M., Javadi, H. R., Melville, M., Oldridge, N. B., \& Gray, D. (2003). Adaptation of the MacNew quality of life questionnaire after myocardial infarction in an Iranian population. Health and Quality of Life Outcomes, I(23), I-6.

Bergman, E., Malm, D., Karlsson, J.-E., \& Berterö, C. (2009). A longitudinal study of patients after myocardial infarction: a sense of coherence, quality of life, and symptoms. Heart \& Lung: The Journal of Critical Care, 38(2), 129-140.

https://doi.org/10.1016/j.hrtlng.2008.05.007

Blakemore, A., Dickens, C., Guthrie, E., Bower, P., Kontopantelis, E., Afzal, C., \& Coventry, P. A. (20/4). Depression and anxiety predict health-related quality of life in chronic obstructive pulmonary disease: systematic review and meta-analysis. International Journal of Chronic Obstructive Pulmonary Disease, 9(I), 50 I-5 12. https://doi.org/I0.2147/COPD.S58136 
Bowling, A. (2005). Measuring Health. A review of Quality of Life Measurement Scales. Third Edition. In Open University Press (Third Edit). Berkshire.

Cella, D., \& Stone, A. A. (2015). Health-Related Quality of Life Measurement in Oncology. American Psychologist, 70(2), 175-185.

Charlson, M. E., Pompei, P., Ales, K. L., \& MacKenzie, C. R. (1987). A new method of classifying prognostic comorbidity in longitudinal studies: Development and validation. Journal of Chronic Diseases, 40(5), 373-383. https://doi.org/10.1016/002 I$968 I(87) 9017 \mid-8$

Choo, J., Burke, L. E., \& Pyo Hong, K. (2007). Improved quality of life with cardiac rehabilitation for post-myocardial infarction patients in Korea. European Journal of Cardiovascular Nursing, 6(3), 166-17I. https://doi.org/I0.1016/j.ejcnurse.2006.07.004

De Gucht, V., Van Elderen, T., Van Der Kamp, L., \& Oldridge, N. (2004). Quality of Life after Myocardial Infarction: Translation and Validation of the MacNew Questionnaire for a Dutch Population. Quality of Life Research, 13(8), I483-I488.

DeSilva, R. A. (20I3). Heart Disease (J. K. Silver, ed.). California: Greenwood.

Dixon, T., Lim, L. L. Y., \& Oldridge, N. B. (2002). The MacNew heart disease health-related quality of life instrument: reference data for users. Quality of Life Research : An International Journal of Quality of Life Aspects of Treatment, Care and Rehabilitation, I I (2), 173-183. https://doi.org/10.1023/A:1015005109731

Ferrans, C. E., Zerwic, J. J., Wilbur, J. E., \& Larson, J. L. (2005). Conceptual model of healthrelated quality of life. Journal of Nursing Scholarship, 37(4), 336-342. https://doi.org/I0.I I I I/j. I547-5069.2005.00058.x

Field, A. (2009). Discovering Statistics Using SPSS 3rd Edition (3rd Editio). https://doi.org// 0.1234/I2345678

Foxwell, R., Morley, C., \& Frizelle, D. (20I3). Illness perceptions, mood and quality of life: A systematic review of coronary heart disease patients. Journal of Psychosomatic Research, 75(3), 2I I-222. https://doi.org/I0.1016/j.jpsychores.2013.05.003

Fredriksson-Larsson, U., Alsen, P., \& Brink, E. (20I3). I've lost the person I used to beExperiences of the consequences of fatigue following myocardial infarction. International Journal of Qualitative Studies on Health and Well-Being, 8(I), I-9. https://doi.org// 0.3402/qhw.v8i0.20836

Guyatt, G. H., Feeny, D. H., \& Patrick, D. L. (1993). Measuring Health-related Quality of Life. Annals of Internal Medicine, I I 8, 622-629. https://doi.org/I0.1016/S009I-6749(97)900002

Hiller, A., Helvik, A. S., Kaasa, S., \& Slørdahl, S. A. (20I0). Psychometric properties of the Norwegian MacNew Heart Disease health-related quality of life inventory. European Journal of Cardiovascular Nursing, 9(3), I46-152. https://doi.org/10.1016/j.ejcnurse.2010.01.002 
Höfer, S., Lim, L., Guyatt, G., \& Oldridge, N. (2004). The MacNew Heart Disease healthrelated quality of life instrument: A summary. Health and Quality of Life Outcomes, 2(3), I-8.

Höfer, S., Saleem, A., Stone, J., Thomas, R., Tulloch, H., \& Oldridge, N. (20I2). The MacNew heart disease health-related quality of life questionnaire in patients with angina and patients with ischemic heart failure. Value in Health, I5(I), I43-I50. https://doi.org/10.1016/j.jval.201 I.07.003

Hosseini, S. H., Ghaemian, A., Mehdizadeh, E., \& Ashraf, H. (20I4). Contribution of depression and anxiety to impaired quality of life in myocardial infarction survivors. International Journal of Psychiatry in Clinical Practice, I-22. https://doi.org/I0.3109/1365/501.2014.940049

Hussain, M. A., Peters, S. A., Woodward, M., Huxley, R. R., \& Al Mamun, A. (2016). The Burden of Cardiovascular Disease Attributable to Major Modifiable Risk Factors in Indonesia. Journal of Epidemiology, 26(10), 515-52I. https://doi.org/10.2188/jea.je20I50178

Kementrian Kesehatan Republik Indonesia. (2013). Riset Kesehatan Dasar. Jakarta.

Kepka, S., Baumann, C., Anota, A., Buron, G., Spitz, E., Auquier, P., ... Mercier, M. (20I3). The relationship between traits optimism and anxiety and health-related quality of life in patients hospitalized for chronic diseases: data from the SATISQOL study. Health and Quality of Life Outcomes, I I, I34. https://doi.org/I0.I I86/I477-7525-I I-I 34

Longmore, R. B., Spertus, J. a., Alexander, K. P., Gosch, K., Reid, K. J., Masoudi, F. a., ... Rich, M.W. (20II). Angina frequency after myocardial infarction and quality of life in older versus younger adults: The Prospective Registry Evaluating Myocardial Infarction: Event and Recovery study. American Heart Journal, I6I(3), 63I-638. https://doi.org/I0.1016/j.ahj.2010.12.005

Martin, L. M., Holmes, S. D., Henry, L. L., Schlauch, K. a., Stone, L. E., Roots, A., ... Ad, N. (20I2). Health-related quality of life after coronary artery bypass grafting surgery and the role of gender. Cardiovascular Revascularization Medicine, 13(6), 321-327. https://doi.org/I0.1016/j.carrev.2012.09.002

Muhammad, I. M., He, H. G., Koh, K., Thompson, D. R., Kowitlawakul, Y., \& Wang, W. (20I4). Health-related quality of life and its predictors among outpatients with coronary heart disease in Singapore. Applied Nursing Research, 27(3), 175-180. https://doi.org/10.1016/j.apnr.2013.11.008

Nakajima, K. M., Rodrigues, R. C. M., Gallani, M. C. B. J., Alexandre, N. M. C., \& Oldridge, N. (2009). Psychometric properties of MacNew Heart Disease Health-related Quality of Life Questionnaire: Brazilian version. Journal of Advanced Nursing, 65(5), 1084-1094. https://doi.org// 0.I I I I/j. I365-2648.2009.04962.x

Norekvål, T. M., Fridlund, B., Moons, P., Nordrehaug, J. E., Sævareid, H. I., Wentzel-Larsen, T., \& Hanestad, B. R. (2010). Sense of coherence - a determinant of quality of life over time in older female acute myocardial infarction survivors. Journal of Clinical Nursing, 19(5-6), 820-83I. https://doi.org/I0.IIII/j.I365-2702.2009.02858.x 
Norris, C. M., Spertus, J. a., Jensen, L., Johnson, J., Hegadoren, K. M., \& Ghali, W. a. (2008). Sex and gender discrepancies in health-related quality of life outcomes among patients with established coronary artery disease. Circulation: Cardiovascular Quality and Outcomes, I(2), I23-130. https://doi.org/I0.1 I6I/CIRCOUTCOMES.108.793448

Pettersen, K. I., Kvan, E., Rollag, A., Stavem, K., \& Reikvam, A. (2008). Health-related quality of life after myocardial infarction is associated with level of left ventricular ejection fraction. BMC Cardiovascular Disorders, 8(Mi), I-9. https://doi.org/I0.1 I86/I47I-226I-828

Smith, K. W., Avis, N. E., Assmann, S. F., Smith, K. W., Avis, N. E., \& Assmann, S. F. (1999). Distinguishing between quality of life and health status in quality of life research : A meta-analysis. Quality of Life Research, 8(5), 447-459.

Sneed, N. V, Paul, S., Michel, Y., Vanbakel, A., \& Hendrix, G. (200I). Evaluation of 3 quality of life measurement tools in patients with chronic heart failure. Heart \& Lung, 30(5), 332-340. https://doi.org/10.1067/mhl.200I.II8303

Van Beek, M. H. C. T., Mingels, M., Voshaar, R. C. O., van Balkom, a. J. L. M., Lappenschaar, M., Pop, G., \& Speckens, a. E. M. (2012). One-year follow up of cardiac anxiety after myocardial infarction: A latent class analysis. Journal of Psychosomatic Research, 73(5), 362-368. https://doi.org/10.1016/j.jpsychores.2012.09.004

Wang, H.-Y., Chew, G., Kung, C.-T., Chung, K.-J., \& Lee, W.-H. (2007). The use of Charlson comorbidity index for patients revisiting the emergency department within 72 hours. Chang Gung Medical Journal, 30(5), 437-444.

Wang, W., Chow, a., Thompson, D. R., Koh, K., Kowitlawakul, Y., \& He, H.-G. (20I4). Predictors of Health-Related Quality of Life Among Patients With Myocardial Infarction. Western Journal of Nursing Research, I-I4. https://doi.org/10.1177/01939459/4546201

World Health Organization. (2004). Global burden of coronary heart disease. In The Atlas of Heart Disease and Stroke.

World Health Organization. (20I4). Noncommunicable Diseases (NCD) Country Profiles: Indonesia. 20I4. Retrieved from http://www.who.int/nmh/countries/idn_en.pdf. 